\section{A Comparative Study of Laparoscopic Pyelolithotomy and Percutaneous Nephrolithotomy in the Management of Large Solitary Renal Pelvic Stone}

\section{Abstract}

Aims and Objectives: The aim of this study is to compare Laparoscopic Retroperitoneal Pyelolithotomy (LRP) and Percutaneous Nephrolithotomy (PCNL) in the management of large $(>2 \mathrm{~cm})$ solitary stones of renal pelvis.

Materials and Methods: This was a prospective randomized study in which patients with solitary renal pelvic stones larger than $2 \mathrm{~cm}$ were randomized in to two groups, LRP Group and (PCNL) Group. The characteristics which were compared between the two groups include operative time, intraoperative complications; postoperative pain assessed by visual analogue scale (VAS) score and analgesic requirement, maximum stone clearance, conversion to open pyelolithotomy, postoperative complications and hospital stay.

Results: Stastiscally there was significant difference between the two groups regarding mean operative time $130.57 \mathrm{~min}$ LRP Group vs. $71.67 \mathrm{~min}$. PCNL Group, $p<0.001$, average blood loss $94.5 \mathrm{ml}$ LRP Group vs. $126.17 \mathrm{ml}$ PCNL Group, $p=0.032$, postoperative pain quantified by VAS score and analgesic requirement 5.06 in first 24 hours LRP Group vs. 2.5 PCNL Group, $p<0.001$, hospital stay 4.96 days LRP Group vs. 3.7 days PCNL Group, $p<0.05$. The Intraoperative and postoperative complications were more in LRP Group than the PCNL group but the difference was not statistically significant. Four patients in the LRP group required conversion to open, however no conversion was required in the PCNL group. No difference was noted in the stone clearance between the two groups.

Conclusion: Percutaneous nephrolithotomy is superior to laparoscopic retroperitoneal pyelolithotomy in the management of large size stones of renal pelvis, in terms of operating time, blood loss, analgesic requirement and hospital stay.

Keywords: Renal pelvic calculus; Randomization; Laparoscopic retroperitoneal pyelolithotomy; Percutaneous nephrolithotomy
Sajad A Para', Sajad A Wani2*, Suhail A Malik, Zafer S Khandy² and Krishna Murty²

1 Department of Urology, Subharti Hospital, Meerut, UP, India

2 Department of General and Minimal Invasive Surgery, Subharti Hospital, Meerut, UP, India

3. Senior registrar Genaral and Minimal Invasive Surgery Subharti hospital, Meerut, UP, India

Corresponding author: Sajad A Wani

Đ ahmadsajadwani@gmail.com

Consultant, Department of General and Minimal Invasive Surgery, Subharti Hospital, Meerut, UP, India.

Tel: +917006749570

Citation: Para SA, Wani SA, Malik SA, Khandy ZS, Murty K (2019) A Comparative Study of Laparoscopic Pyelolithotomy and Percutaneous Nephrolithotomy in the Management of Large Solitary Renal Pelvic Stone. J Univer Surg. Vol.7 No. 2:4

Received: September 09, 2019; Accepted: October 17, 2019; Published: October 25, 2019

\section{Introduction}

The life time prevalence of kidney stone disease is estimated at $1 \%-15 \%$, with the probability of having a stone varying according to age, gender, race and geographic location [1]. The primary goal of surgical stone management is to achieve maximum stone clearance with minimal morbidity to patient. Various surgical treatment options available include:
1. Extracorporeal shock wave lithotripsy (ESWL) [2].

2. Percutaneous nephrolithotomy (PCNL) [3].

3. Combination of both techniques, SWL \& PCNL [4].

4. Retrograde ureteroscopic intra-renal stone disintegration using flexible ureteroscope and laser as an energy source (RIRS) [5]. 


\section{Laparoscopic procedures:}
a) Laparoscopic pyelolithotomy
b) Laparoscopic nephrolithotomy

6. Open surgery:
a) Open pyelolithotomy
b) Open nephrolithotomy

The ideal procedure to deal with large renal stones would be the one that achieve complete stone free status with minimal morbidity and with the least number of procedures. The traditional standard procedure was open nephrolithotomy, which evolved into PCNL or Retrograde Intrarenal Surgery and Laparoscopic Pyelolithotomy (LPL) [6].

With the recent development of technique in laparoscopic surgery, Laparoscopic Pyelolithotomy (LPL) has been frequently considered as an effective procedure in the management of large renal stones. There are some advantages to LPL, the first and most obvious advantage is that most of the stones can be removed integrally, ability to minimize bleeding, lessen pain, and lower morbidity. However, despite the potential advantages of LPL, its usage is rare [7]. Percutaneous Nephrolithotomy (PCNL) is effective for large renal stones. It is minimally invasive procedure with higher Stone-free Rate (SFR), but there are still serious complications such as bleeding and postoperative sepsis [8]. Size of the stone is directly correlating with the overall incidence of complications after PCNL [9].

One prior meta-analysis evaluated the efficacy and safety of LPL and PCNL in treating large renal stones and found that PCNL and LPL were effective and safe for managing this condition [10]. Recently, several additional clinical trials have been reported that compared PCNL and LPL for removal of large renal stones [7].

The present study has been undertaken to compare the two minimally invasive surgical procedures, laparoscopic Pyelolithotomy and percutaneous nephrolithotomy for the treatment of large $(>2 \mathrm{~cm})$ stones of renal pelvis and to evaluate the merits and demerits of each procedure.

\section{Research Methodology}

This was a prospective randomized study between February 2012 and November 2018. Patients with age more than 15 years, size of calculus $>2 \mathrm{~cm}$, located within renal pelvis were included in the study. Patients with uncorrected coagulopathy, pregnant female patients, extensive prior abdominal and retroperitoneal surgeries, PUJ obstruction with secondary calculi and patients with ureteric stricture were excluded from the study. The patients qualifying for the study were randomly subjected to LRP and PCNL by simple randomization method and the results were analyzed statistically after applying appropriate tests to each result by SPSS software. The following characteristics were compared between the LRP and PCNL groups.

1. Operative time.

2. Intraoperative complications.
3. Hemorrhage requiring blood transfusion.

4. Postoperative pain assessed by VAS score and analgesic requirement.

5. Maximum stone clearance.

6. Conversion to open pyelolithotomy.

7. Postoperative complications.

8. Hospital stay.

\section{Results and Discussion}

120 patients of renal stone disease who were subjected to laparoscopic pyelolithotomy (LRP) (60) and percutaneous nephrolithotomy (PCNL) (60) from Feb 2012 to Nov 2018. Preoperative (age, sex, side of the stone, stone size), intraoperative (operative time, complications, blood loss, conversion to open) and postoperative parameters (VAS score, stone clearance, postoperative complication, hospital stay) were shown in Tables 1-3 respectively.

As with any technology-driven field, both laparoscopic surgery and endourology have made tremendous progress in recent years. The surgical treatment of urinary stone disease has evolved from primarily an open route to the minimally invasive

Table 1 Pre-operative parameters.

\begin{tabular}{|c|ccc|c|}
\hline Pre-op parameters & LRP & PCNL & P value \\
\hline Age (Mean) & 38.53 years & 38.42 years & $>0.05$ \\
\hline Sex (M:F) & $34: 26$ & $28: 32$ & $=0.605$ \\
\hline $\begin{array}{c}\text { Laterality of disease (Right: } \\
\text { Left: Bilateral) }\end{array}$ & $30: 22: 8$ & $26: 20: 14$ & $=0.603$ \\
$\begin{array}{c}\text { Previous abdominal surgery } \\
\text { Stone size (Mean) }\end{array}$ & 6 & 7 & $=1$ \\
\hline
\end{tabular}

Table 2 Intra-operative parameters.

\begin{tabular}{|c|c|c|c|}
\hline $\begin{array}{c}\text { Intra-op } \\
\text { parameters }\end{array}$ & LRP & PCNL & P value \\
\hline $\begin{array}{c}\text { Operative time } \\
\text { Complications } \\
\text { (Major \& Minor) }\end{array}$ & $130.57 \pm 9.45 \mathrm{~min}$ & $71.67 \pm 21.96$ & $<0.001$ (Sig.) \\
\hline Conversion to open & $13.34 \%$ & $10 \%$ & $>0.05$ (Non sig.) \\
\hline Blood loss (Mean) & $94.50 \pm 50.67 \mathrm{ml}$ & $\begin{array}{c}126.17 \pm 61.02 \\
\mathrm{ml}\end{array}$ & $\mathrm{P}=0.032$ (Sig.) \\
\hline
\end{tabular}

Table 3 Post-operative parameters.

\begin{tabular}{c|c|c|c|}
$\begin{array}{c}\text { Post-op } \\
\text { parameters }\end{array}$ & LRP & PCNL & P value \\
$\begin{array}{c}\text { VAS score in } \\
\text { first } 24 \text { hrs }\end{array}$ & $5.06 \pm 1.52$ & $2.5 \pm 1.04$ & $<0.001$ (Sig.) \\
\hline $\begin{array}{c}\text { Analgesic } \\
\text { requirement in } \\
\text { first } 24 \text { hrs }\end{array}$ & $\begin{array}{c}2 \pm 0.742 \\
\text { (Ampoules of }\end{array}$ & $\begin{array}{c}1.4 \pm 0.674 \\
\text { (Ampoules of }\end{array}$ & $<0.05$ (Sig.) \\
$\begin{array}{c}\text { Stone } \\
\text { clearance }\end{array}$ & $96.67 \%$ & $93.34 \%$ & $>0.05$ (Non sig.) \\
\hline $\begin{array}{c}\text { Post op } \\
\text { complications }\end{array}$ & $23.34 \%$ & $13.34 \%$ & $>0.05$ (Non sig.) \\
\hline $\begin{array}{c}\text { Hospital stay } \\
\text { Tramal } 100 \mathrm{mg})\end{array}$ & $4.96 \pm 2.37$ days & $3.7 \pm 1.17$ & $<0.05$ (Non sig.) \\
\hline
\end{tabular}


methods like ESWL, Ureteroscopy, PCNL and RIRS. These new and minimally invasive modalities have markedly decreased the morbidity associated with the classical open surgeries In the present study which consisted of 120 patients ( 60 patients in LRP group and 60 patients in PCNL group) the overwhelming majority of the patients were in their reproductive age group (2040 years). There were more males than females in the LRP group whereas converse was true in case of PCNL group. However the most common age group was $20-40$ years in both the groups.

We performed our procedures on renal stones that were larger than $2 \mathrm{~cm}$ and located in renal pelvis. The mean stone size was $3.08 \mathrm{~cm}$ in laparoscopic group where as it was $3.35 \mathrm{~cm}$ in PCNL group. The difference between the two groups was stastiscally not significant $(p=0.07)$. Apul et al. [11] performed their comparative study in which mean stone size in LRP and PCNL group were 3.6 $\mathrm{cm}$ and $4.2 \mathrm{~cm}$ respectively. Alireza et al. [12] conducted their comparative study with mean stone size in laparoscopic group and PCNL group was $3.53 \pm 0.733$ and $3.66 \pm 0.07 \mathrm{~cm}$ respectively.

There was stastiscally significant difference in average operating time between the two groups. In our study the mean operative time for LRP group was $130.57 \pm 9.45$ which was much longer than that of PCNL group having average duration of procedure $71.67 \pm 21.96(p<0.001)$. Apul et al. [11] reported an average operating time of 142.18 and $71.6 \mathrm{~min}$ in LRP and PCNL group respectively. Maria et al. [13] reported an average operating time of 129 and 75 min in LRP and PCNL group respectively. Khalil et al. [14] reported an average operating time of $130.6 \pm 38.7$ and $108.5 \pm 18.7 \mathrm{~min}$ in LRP and PCNL group respectively. Ahmet et al. [15] reported an average operating time of $138.40 \pm 51.19$ (range 70-240 $\mathrm{min}$ ) and $57.92 \pm 21.12 \mathrm{~min}$ (range 40-110 $\mathrm{min}$ ) in LRP and PCNL group respectively. The less operating time for PCNL can be attributed to the surgeon's expertise in doing PCNL. Thus average operating time in LRP and PCNL group respectively in this study is comparative to the international results.

The average blood loss in LRP was $94.5 \pm 50.67 \mathrm{ml}$ (range 95$305 \mathrm{ml}$ ) and $3.34 \%$ of patients in this group required blood transfusions compared to PCNL were average blood loss was $126.17 \pm 61.02 \mathrm{ml}$ (range $85-345 \mathrm{ml}$ ) and $6.67 \%$ of patients required blood transfusion. The difference was stastiscally significant $(p<0.05)$. Apul et al. [11] reported in their study an average estimated blood loss of $173.1 \mathrm{ml}$ in LRP as compared to $147.9 \mathrm{ml}$ for PCNL group. Maria et al. [13] reported in their study bleeding occurred in $18 \%$ of patients who had undergone PCNL and only $6.25 \%$ of total patients required blood transfusion. Ahmet et al. [15] reported in their study the mean drop in post op hemoglobin level of $0.9 \pm 0.6$ (range $0-2$ ) g/dl in LRP and 1.7 \pm 1.1 (range 0-4) g/dl in PCNL group. The average blood loss in this study is less than in other mentioned studies and that the number of patients required blood transfusion is less too.

In our study a total of 12 (20\%), four major and eight minor, intraop complications occurred in the LRP group. Four patients had bleeding that could not be controlled laparoscopically and were converted to open, four patients had migration of stones into the calyx that were not accessible laparoscopically and required conversion to open, peritoneal breach occurred in four patients where a veress needle was used to let the gas out of peritoneal cavity and the rent was closed primarily. In PCNL group we had six complications (10\%). One patient had a pleural breach that required intra-costal tube drainage and two patients had bleeding that required blood transfusion. The difference between the two groups was stastiscally not significant $(p>0.5)$. Li et al. [16] reported a major complication rate of $5.3 \%$ in standard PCNL. Syed et al. [17] review the records of 671 patients who had undergone PCNL and reported that complications occurred in 203 (30.3\%) patients, renal parenchymal injury in 103 (15.4\%), perioperative bleeding in $42(6.3 \%)$, late bleeding in $6(0.9 \%)$ renal collecting duct injury in 35 (5.2\%), fever in $7(1 \%)$ colon perforation in 2 $(0.3 \%)$ major vessel injury in $3(0.4 \%)$ pneumothorax in $3(0.4 \%)$ and hemothorax in $2(0.3 \%)$ subjects. Mortality occurred in one patient with colonic perforation $(0.15 \%)$.

Of all the laparoscopic procedures, eight were converted to open, while the rest were completed successfully. The conversion rate of LRP group was $13.34 \%$. The reason for conversion was bleeding in four and stone migration in four patients. Where as in PCNL group all the procedures were completed successfully and no patient needed conversion. Apul et al. [11] and Maria et al. [13] reported similar results.

There was a clearance rate of $96.67 \%$ in LRP group and $93.34 \%$ in PCNL group. The clearance was checked in the postoperative $X$-Ray KUB. In PCNL group incomplete clearance in two cases was attributed to migration of fragments into the calyces during the lithotripsy. In LRP group it was the inadvertent fragmentation of the calculus that resulted in incomplete clearance.

Maria et al. [13] reported a stone free rate of $88 \%$ and $82 \%$ in LRP and PCNL group respectively in their study. Khalil et al. [14] reported a stone free rate of $100 \%$ and $96 \%$ in LRP and PCNL group respectively in their study. Alireza et al. [12] reported a stone free rate of $100 \%$ and $76.7 \%$ in LRP and PCNL group respectively in their study. In our study, clearance rate is almost similar to other authors.

The average analgesic requirement in LRP and PCNL group was 2 \pm 0.74 and $1.4 \pm 0.674$ ampoules of Tramadol $(100 \mathrm{mg})$ in first 24 hours. The difference was stastiscally significant $(p<0.05)$. Yasser et al. [18] reported that analgesia (6.6 morphine equivalents) was needed only for $2.2 \pm 0.9$ days (range 1.3-3.1) and $2.4 \pm$ 0.9 days (range 1.5-3.3) in the PNL and LPL groups respectively. Khalil et al. [14] reported that in LRP and PCNL the mean time of post-operative analgesia was $2.2 \pm 0.9$ days vs. $2.4 \pm 0.9$ days respectively.

There were a total of 22 complications in the postoperative period, $14(23.33 \%)$ in the Laparoscopic and $8(13.34 \%)$ in the PCNL group. Four patients in the Laparoscopic group had prolonged urinary leak that responded to conservative management, six had wound infection that responded to antibiotics, two had prolonged ileus and two had surgical emphysema. In PCNL group there were eight complications, two patient had bleeding that required blood transfusion and responded to conservative treatment, two had stent migration into the bladder with urinary retention, two had wound infection that responded to antibiotics and local wound 
care, and two had perinephric collection that required catheter drainage. The difference was stastiscally not significant. Maria et al. [13] reported post-operative complication rate of $12 \%(2 / 16)$ and $18 \%(3 / 16)$ in Laparoscopic and PCNL group respectively. In Laparoscopic group it was the urinary leak in 2 patients and in PCNL group it was bleeding in 3 patients. Syed et al. [17] reported in their study of 671 patients who had undergone PCNL at their center, late bleeding in 6 (0.9\%), fever in 7 (1\%).

The mean hospital stay in the LRP and PCNL group were $4.96 \pm$ 2.37 and $3.7 \pm 1.17$ respectively. The mean hospital stay was less in PCNL group than LRP group and the difference was stastiscally significant $(p<0.05)$. Apul et al. [11] reported in their study the average hospital stay of 3.8 and 3 days in LRP and PCNL group respectively. Maria et al. [13] reported in their study of 16 patients, the average hospital stay of 6.5 and 5.6 days in LRP and

\section{References}

1 Norlin A, Lindell B, Granberg PO, Lindvall N (1976) Urolithiasis: A study of its frequency. Scand J Urol Nephrol 10: 150-153.

2 Chanssy C, Schmiedt E (1984) Extracorporeal shock wave lithotripsy (ESWL) for kidney stones, An alternative to surgery? Urol Radiol 6: 80-87.

3 Lam HS, Lingeman JE, Barron M (1992) Staghorn calculi: Analysis of treatment results between initial percutaneous nephrolithotomy and extracorporeal shock wave lithotripsy monotherapy with reference to surface area. J Urol 147: 1219-1225.

4 Lam HS, Lingeman JE, Mosbaugh PG, Steele RE, Knapp PM, et al. (1992) Evolution of the technique of combination therapy for staghorn calculi, adecreasing role of ESWL. J Urol 148: 1058-1062.

5 Auge BK, Dahm P,Wu NZ (2001) Ureteroscopic management of lower pole renal calculi; technique of calculus displacement. J Endourol 15: 835-838.

6 Zeng G, Zhu W, Li J, Zhao Z, Zeng T, et al. (2015) The comparison of minimally invasive percutaneous nephrolithotomy and retrograde intrarenal surgery for stones larger than $2 \mathrm{~cm}$ in patients with a solitary kidney: A matched-pair analysis. World J Urol 33: 1159-1164.

7 Yunjin B, Yin T, Lan D, Xiaoming W, Yubo Y, et al. (2017) Management of large renal stones: laparoscopic pyelolithotomy versus percutaneous nephrolithotomy. BMC Urology 17: 75.

8 Seitz C, Desai M, Hacker A, Hakenberg OW, Liatsikos E, et al. (2012) Incidence, prevention, and management of complications following percutaneous nephrolitholapaxy. Eur Urol 61: 146-158.

9 Turna B, Umul M, Demiryoguran S, Altay B, Nazli O (2007) How do increasing stone surface area and stone configuration affect overall outcome of Percutaneous Nephrolithotomy? J Endourol 21:34-43.

10 Wang X, Li S, Liu T, Guo Y, Yang Z (2013) Laparoscopic pyelolithotomy
PCNL group respectively. Khalil et al. [14] reported in their study, the average hospital stay of $4.5 \pm 1.9$ days and $4.4 \pm 1.4$ days in LRP and PCNL group respectively.

\section{Conclusion}

Percutaneous nephrolithotomy is superior to laparoscopic retroperitoneal pyelolithotomy in the management of large size stones of renal pelvis, in terms of operating time, analgesic requirement and hospital stay. PCNL has an acceptable stone clearance rate, low rate of conversion to open surgery, less hospital stay and an acceptable overall complication rate.

\section{Conflict of Interest}

There is no conflict of interest.

compared to percutaneous nephrolithotomy as surgical management for large renal pelvic calculi: A meta-analysis. J Urol 190: 888-893.

11 Goel A, Hemal AK (2003) Evaluation of role of Retroperitoneoscopic pyelolithotomy and its comparison with percutaneous nephrolithotomy. Int Urol Nephrol 35:73-76.

12 Alireza A, Mohammad MH, Abbasali K (2013) Laparoscopic pyelolithotomy versus percutaneous nephrolithotomy for a solitary renal pelvic stone larger than $3 \mathrm{~cm}$ : A prospective study. Urolithiasis 41: 493-497.

13 Maria P, Stephane M, Francois D, Pierre M, Jean MD, et al. (2005) Management of pelvic stones larger than $20 \mathrm{~mm}$ : Laparoscopic Transperitoneal pyelolithotomy or percutaneous nephrolithotomy. International Urol Intl 75: 322-326.

14 Khalil AM, Hassabo M, Hanafi A, Abdul-Halim H (2011) Management of solitary renal pelvic stone: Laparoscopic Retroperitoneal pyelolithotomy versus percutaneous nephrolithotomy. J Endourol 25: 975-978.

15 Ahmet T, Abdulkadir T, Tolga A, Muzaffer A, Murat B (2012) The comparison of laparoscopic pyelolithotomy and percutaneous nephrolithotomy in the treatment of solitary large renal pelvic stone. Urol Res 40: 549-555.

16 Li X, Zeng GH, Yuan J, Wu KJ, Shan CC, et al. (2004) Treatment of upper urinary calculi with the PCNL technique (experience of 20 years). Beijing Da Xue Xue Bao 36: 124-126.

17 Syed HMB, Sasan M, Mohammad KM (2011) Percutaneous nephrolithotomy complications in 671 consecutive patient: A single center experience. J Urol 8: 271-276.

18 Haggag YM, Morsy G, Badr MM, Al-Emam AB, Farid $M$, et al. (2013) Comparative study of Laparoscopic pyelolithotomy versus percutaneous nephrolithotomy in the management of large renal pelvic stone. Can Urol Assoc J 7: E171. 